Abstracta Iranica

Revue bibliographique pour le domaine irano-aryen

Volume 37-38-39 | 2018

Comptes rendus des publications de 2014-2016

\title{
Peter Christensen. The Decline of Iranshahr. Irrigation and Environment in the Middle East, 500 BC-AD 1500
}

\section{Camille Rhoné-Quer}

\section{OpenEdition}

1 Journals

\section{Édition électronique}

URL : http://journals.openedition.org/abstractairanica/47407

DOI : 10.4000/abstractairanica.47407

ISBN : 1961-960X

ISSN : 1961-960X

Éditeur :

CNRS (UMR 7528 Mondes iraniens et indiens), Éditions de l'IFRI

Référence électronique

Camille Rhoné-Quer, «Peter Christensen. The Decline of Iranshahr. Irrigation and Environment in the Middle East, 500 BC-AD 1500 », Abstracta Iranica [En ligne], Volume 37-38-39| 2018, document 1, mis en ligne le 30 décembre 2018, consulté le 28 septembre 2020. URL : http://journals.openedition.org/ abstractairanica/47407 ; DOI : https://doi.org/10.4000/abstractairanica.47407

Ce document a été généré automatiquement le 28 septembre 2020.

Tous droits réservés 


\title{
Peter Christensen. The Decline of Iranshahr. Irrigation and Environment in the Middle East, 500 BC-AD 1500
}

\author{
Camille Rhoné-Quer
}

\section{RÉFÉRENCE}

Peter Christensen. The Decline of Iranshahr. Irrigation and Environment in the Middle East, 500 BC-AD 1500. Trad. Steven Sampson, London-New York: I. B. Tauris, (1993) 2016, XIV-347 p., ISBN 978-1-78453-318-2

1 Ce livre est la réédition - sans révision - chez I. B. Tauris (2016) du texte fondateur que Peter Christensen a publié en 1993 aux Museum Tusculanum Press de Copenhague à partir de sa thèse soutenue en 1991. Le postulat de Christensen au début des années 1990, selon qui les historiens européens considèrent que le « Moyen-Orient » aurait été victime d'un long processus de déclin dès les premiers siècles abbassides (chap. 2) et l'attribuent à quatre facteurs - la désertification, les invasions nomades, l'islam et le despotisme oriental -, doit aujourd'hui largement être mis à jour à l'aune de l'apport significatif des nombreux travaux publiés depuis 25 ans dans le champ de l'histoire de l'Islam. Outre de brèves introduction et conclusion, l'ouvrage compte vingt chapitres, de longueur très inégale, organisés en quatre parties. La première partie fait office d'introduction étoffée. Les trois parties suivantes sont découpées géographiquement et portent successivement sur la Mésopotamie et le Khuzistan, les oasis du plateau iranien et le Sistan. Les annexes, conséquentes, incluent une bibliographie certes importante mais qui n'a pas été mise à jour, ainsi que des notes et index.

Christensen s'intéresse à l'Iranshahr - entre Euphrate et Amou Darya - et au rôle que les changements dans le domaine de l'irrigation ont pu avoir dans les processus historiques. Son approche, résolument macro-historique, mène l'auteur à embrasser la période allant de la conquête de Babylone par Cyrus (539 av. n. è.) à la prise de Bagdad 
par Soliman le Magnifique (1534). Il s'intéresse en particulier aux interactions entre nature et société : investissement humain dans la construction et l'entretien des systèmes d'irrigation, maintien de pratiques agricoles, impact des accidents naturels ou artificiels, rythmes de l'occupation humaine, etc. L'étude des trois zones géographiques choisies par l'auteur lui permet de proposer une analyse des rapports - équilibre, déséquilibre et/ou complémentarité - entre les trois aires constitutives de l'Iranshahr. Sur le long terme, il constate le déclin de la Mésopotamie et l'incapacité des deux régions voisines à compenser cette tendance. Si les invasions mongoles et turkomongoles ont joué un rôle dans ce déclin, ce sont aussi et surtout des facteurs environnementaux qui sont convoqués ici par l'auteur comme éléments explicatifs. L'auteur conclut en abordant la question du coût des armées étatiques, impossibles à financer dans un tel contexte d'effondrement de l'exploitation agricole et donc du système fiscal, ce qui aurait contribué à l'avènement des armées nomades.

\section{AUTEURS}

\section{CAMILLE RHONÉ-QUER}

Université d'Aix-Marseille 